\title{
Decision to delivery interval and associated factors for emergency cesarean section: a cross-sectional study
}

Tebabere Moltot Kitaw ${ }^{1 *}$, Simachew Kassa Limenh², Fantahun Alemnew Chekole², Simegnew Asmer Getie ${ }^{2}$, Belete Negese Gemeda ${ }^{3}$ and Abayneh Shewangzaw Engda ${ }^{3}$

\begin{abstract}
Background: Emergency cesarean section is a commonly performed surgical procedure in pregnant women with life-threatening conditions of the mother and/or fetus. According to the Royal College of Obstetricians and Gynecologists and the American College of Obstetricians and Gynecologists, decision to delivery interval for emergency cesarean sections should be within $30 \mathrm{~min}$. It is an indicator of quality of care in maternity service, and if prolonged, it constitutes a third-degree delay. This study aimed to assess the decision to delivery interval and associated factors for emergency cesarean section in Bahir Dar City Public Hospitals, Ethiopia.

Method: An institution-based cross-sectional study was conducted at Bahir Dar City Public Hospitals from February to May 2020. Study participants were selected using a systematic random sampling technique. A combination of observations and interviews was used to collect the data. Data entry and analysis were performed using Epi-data version 3.1 and SPSS version 25, respectively. Statistical significance was set at $p<0.05$.

Result: Decision-to-delivery interval below 30 min was observed in $20.3 \%$ [95\% Cl=15.90-24.70\%] of emergency cesarean section. The results showed that referral status [AOR $=2.5,95 \% \mathrm{Cl}=1.26-5.00]$, time of day of emergency cesarean section $[A O R=2.5,95 \% \mathrm{Cl}=1.26-4.92]$, status of surgeons $[A O R=2.95,95 \% \mathrm{Cl}=1.30-6.70]$, type of anesthesia $[A O R=4,95 \% \mathrm{Cl}=1.60-10.00]$ and transfer time $[A O R=5.26,95 \% \mathrm{Cl}=2.65-10.46]$ were factors significantly associated with the decision to delivery interval.

Conclusion: Decision-to-delivery intervals were not achieved within the recommended time interval. Therefore, to address institutional delays in emergency cesarean section, providers and facilities should be better prepared in advance and ready for rapid emergency action.
\end{abstract}

Keywords: Decision to delivery interval, Emergency cesarean section, Public hospitals, Bahir Dar, Ethiopia

\footnotetext{
* Correspondence: mtebabere@gmail.com

'Department of Midwifery, College of Health Science, Debre Berhan University, Debre Berhan, Ethiopia

Full list of author information is available at the end of the article
}

(c) The Author(s). 2021 Open Access This article is licensed under a Creative Commons Attribution 4.0 International License, which permits use, sharing, adaptation, distribution and reproduction in any medium or format, as long as you give appropriate credit to the original author(s) and the source, provide a link to the Creative Commons licence, and indicate if changes were made. The images or other third party material in this article are included in the article's Creative Commons licence, unless indicated otherwise in a credit line to the material. If material is not included in the article's Creative Commons licence and your intended use is not permitted by statutory regulation or exceeds the permitted use, you will need to obtain permission directly from the copyright holder. To view a copy of this licence, visit http://creativecommons.org/licenses/by/4.0/. The Creative Commons Public Domain Dedication waiver (http://creativecommons.org/publicdomain/zero/1.0/) applies to the data made available in this article, unless otherwise stated in a credit line to the data. 


\section{Background}

Emergency cesarean section (EmCS) is a surgical procedure that is performed when there is an immediate threat to the life of a fetus and/or woman [1]. The period between a decision to perform EmCS and the actual delivery of the neonate is called decision to delivery interval (DDI) [1, 2]. It includes patient and theater preparation time, anesthetic time, and the skin incision to delivery interval [3]. According to Royal College of Obstetricians and Gynecologists (RCOG) and American College of Obstetricians and Gynecologists (ACOG), the recommended decision to delivery interval (DDI) is within 30 min $[1,4]$.

Cesarean section (CS) can improve infant and/or maternal outcomes only when used appropriately [5]. Therefore, hospitals providing obstetric care should be able of respond to obstetric emergencies within the recommended time $[2,6,7]$. Despite this, in developing nations, reviews reported that difficulty in achieving the recommended $30 \mathrm{~min}$ DDI [8-11] and fetal deaths occurred while waiting for EmCS [9]. This indicates that in developing nations, women in labor need timely access to skilled care.

In Ethiopia, the EmCS access is high [12, 13]. However, similar to other developing nations, poor neonatal outcomes after delivery by EmCS are high [14]. This results in psychological and physical trauma to the mother. Even though the procedure of cesarean section is complex and multidisciplinary, and some laboring women need stabilization before the procedure $[3,9]$. In case of an emergency cesarean section, DDI must be considered to be completed in the target [4]. DDI remains an important indicator for evaluating the quality of maternity care in EmCS [1, 14, 15]. Therefore, this study aimed to assess DDI and its associated factors in Bahir Dar City Public Hospitals, Ethiopia.

\section{Methods}

Study setting, period, and participants

An institution-based cross-sectional study was conducted from February 26, 2020, to May 26, 2020, in Bahir Dar city public hospitals, the capital of Amhara region, northwest Ethiopia. This city has three public hospitals; among these two are referral hospitals and one primary hospital. These hospitals service for over $7,000,000$ populations and have a total of 160 skilled birth attendants. All these hospitals have 52 beds for labor and delivery services and approximately 13, 920 deliveries per year. All women who underwent EmCS at Bahir Dar City Public Hospitals were the source population. Therefore, all women who underwent EmCS during the study period at Bahir Dar City public hospitals were the study population. In this study, women who underwent EmCS during the study period were included.

\section{Sample size and sampling procedure}

The sample size was calculated using the single population proportion formula with the assumption of $95 \% \mathrm{CI}$, and $12 \%$ of women who had recommended decision to delivery interval in Tanzania [10]. A 10\% non-response rate and $3.7 \%$ margin of error were used to obtain a sample size of 327. The total sample size was proportionally allocated for all three hospitals based on the last year's similar three-month EmCS report. Eligible women in each hospital were invited to participate using a systematic random sampling technique. The sampling fraction was determined by dividing the total threemonth EmCS rate in each hospital by the sample size, which was proportionally allocated in each hospital. The first participant was selected using the lottery method and every 2 nd interval in each hospital was included in the study.

\section{Data collection tools and technique}

The questionnaire was developed after an extensive review of the literature (Supplementary file 1). The tool was modified and finalized based on the suggestions and recommendations of the local experts. A structured interview questionnaire and observational checklist were used for data collection. One supervisor and two Bachelor of Science (BSc) midwives were employed as data collectors. Training was provided to the data collectors and the research supervisor. A pretest was conducted with $33(10 \%)$ women who underwent emergency cesarean section randomly chosen from a population outside the study area. Questionnaires were cleaned daily by the data collection supervisor under the primary investigator's oversight. Questionnaires were checked for completeness and consistency, and when missing items were discovered, the items were collected and coded appropriately. The collected data were checked for completeness and consistency by the supervisor under the guidance of the primary investigator.

\section{Variables and measurements}

Independent variables in this study were classified into seven sections: socio-demographic factors, including age, educational status, marital status, place of residence, and occupation. Obstetric factors included ANC follow-up, gravidity, parity, and number of live children. Presence of cesarean scare, stage of labor at decision, referral status, and an indication of EmCS. The Time of day and day of the week of EmCS, preoperative related factors include preoperative stabilization need, hesitation for consent, transfer time interval, and presence of material for preparation. Surgeon status, type of anesthesia, and operative room-related variables were also examined as potential predictors to assess the decision to delivery interval. The dependent variable in this study was decision to delivery interval. 


\section{Operational definition}

Emergency cesarean section

This is based on a binary classification system for cesarean section [6].

$D D I$

After calculating to the nearest minute, $30 \mathrm{~min}$ was used as a cutoff point to say recommended/delayed $[4,16]$.

\section{Transfer time}

The time taken from the decision for EmCS to arrival in the operation theater and $15 \mathrm{~min}$ was used as the cut-off point to say delayed or not $[9,17]$.

\section{Operation time}

Time taken from skin incision to delivery of the fetus and 5 min used as a cutoff point to say delayed or not [18].

\section{Data management and analysis}

Before analysis, completeness and consistency of each questioner were checked, coded and entered into Epi data version 3.1, and then exported to SPSS version 25 for data cleaning, recoding and analysis. Categorical variables are presented as frequencies and percentages. Bivariable and multivariable logistic regression analysis were performed to identify the independent predictors of the outcome variable. Hosmer and Lemeshow goodness of fit test $(p=0.85)$ and variance inflation factor were done to check model fitness and problem of multicollinearity respectively. Variables with a $p$-value $\leq 0.25$, in the bivariable logistic regression analysis, were entered into a multivariable logistic regression model. Variables with a p-value $<0.05$ with $95 \%$ confidence interval (CI) for Adjusted odds ratio (AOR) were considered statistically significant.

\section{Result}

Socio-demographic characteristics

A total of three hundred twenty-five women were enrolled in this study, with a response rate of $99.4 \%$. The median age (interquartile range (IQR)) of the respondents was $26(23-30)$ years. Nearly one-third (37.8\%) of the respondents were between the ages of 25-29 years and more than two-thirds (70.2\%) of the study subjects were urban residents (Table 1 ).

\section{Obstetrical characteristics of respondents}

The findings showed that $48.3 \%$ of the respondents were nulliparous. Almost two-thirds of the respondents had four or more antenatal care (ANC) visits. Thirty-nine (12\%) participants had a previous history of cesarean section (Table 2).

In this study, non-reassuring fetal heartbeat patterns (NRFHBP) were the most common indication for
Table 1 Socio-demographic characteristics of respondents $(n=325)$

\begin{tabular}{lll}
\hline Variable & Categories & $\mathbf{n}(\%)$ \\
\hline AGE in Years & $<20$ (all are above 18) & $13(4)$ \\
& $20-24$ & $94(28.9)$ \\
& $25-29$ & $123(37.8)$ \\
& $30-34$ & $61(18.8)$ \\
& $\geq 35$ & $34(10.5)$ \\
Marital Status & Single & $14(4.3)$ \\
& Married & $304(93.5)$ \\
Educational Status & Divorced & $7(2.2)$ \\
& No Formal Education & $111(34.2)$ \\
& Primary School & $70(21.5)$ \\
Occupational Status & Secondary School & $69(21.2)$ \\
& Collage / university & $75(23.1)$ \\
& Government Employee & $53(16.3)$ \\
& House Wife & $192(59.1)$ \\
Place of Residence & Daily Labor & $30(9.2)$ \\
& Merchant & $39(12)$ \\
& Others & $11(3.4)$ \\
& Urban & $228(70.2)$ \\
& Rural & $97(29.8)$ \\
\hline
\end{tabular}

a(student, non-governmental employee)

emergency cesarean section, which accounted for $78(24 \%)$ of cases followed by cephalopelvic disproportion (CPD) 64(19.7\%). The lowest median time was recorded for cord prolapse, whereas the highest was for failed induction (Table 3).

Table 2 Obstetrical characteristics of respondents $(n=325)$

\begin{tabular}{|c|c|c|}
\hline Characteristics & Categories & $n(\%)$ \\
\hline \multirow[t]{3}{*}{ Gravidity } & Primigravidia & $150(46.2)$ \\
\hline & Multigravida & $150(46.2)$ \\
\hline & Grand multipara & $25(7.6)$ \\
\hline \multirow[t]{4}{*}{ Parity } & Nulliparous & 157(48.3) \\
\hline & Primiparous & $80(24.6)$ \\
\hline & Multiparous & $73(22.5)$ \\
\hline & Grand multiparous & $15(4.6)$ \\
\hline \multirow[t]{5}{*}{ ANC follow up } & First visit & $6(1.8)$ \\
\hline & Second visit & $16(4.9)$ \\
\hline & Third visit & 64(19.7) \\
\hline & Fourth and above & $222(68.3)$ \\
\hline & No ANC follow up & $17(5.3)$ \\
\hline \multirow[t]{2}{*}{$\mathrm{BPCR}^{\mathrm{a}}(n=308)$} & Yes & 233(75.65) \\
\hline & No & $75(24.35)$ \\
\hline \multirow[t]{2}{*}{ Scared Uterus } & Yes & $39(12 \%)$ \\
\hline & No & $286(88 \%)$ \\
\hline
\end{tabular}

${ }^{a} B P C R$ Birth preparedness and complication readiness plan 
Table 3 Indication for emergency cesarean section $(n=325)$

\begin{tabular}{|c|c|c|c|c|}
\hline \multirow[t]{2}{*}{ Indication } & \multicolumn{2}{|c|}{ Decision to Delivery Time } & \multirow[t]{2}{*}{ Total } & \multirow{2}{*}{$\begin{array}{l}\text { Median (IQR) } \\
\text { min }\end{array}$} \\
\hline & Within $30 \mathrm{~min}$ & After $30 \mathrm{~min}$ & & \\
\hline Cord Prolapse & 7 & 0 & 7 & $25(20-26)$ \\
\hline $\mathrm{APH}^{\mathrm{a}}$ & 6 & 14 & 20 & $37(30-44.5)$ \\
\hline NRFHBP ${ }^{b}$ & 10 & 68 & 78 & $43(35-40)$ \\
\hline$C P D^{c}$ & 9 & 55 & 64 & $40(35-40)$ \\
\hline Failed Induction & 5 & 14 & 19 & $48(30-63)$ \\
\hline Failed $\mathrm{VBAC}^{* 4}$ and $>1$ Scar at Labor & 7 & 32 & 39 & $36(34-45)$ \\
\hline Breech & 5 & 25 & 30 & $42.5(35-56.5)$ \\
\hline Grade III Meconium at Latent stage & 10 & 36 & 46 & $42.5(34-55.25)$ \\
\hline Arrest/Protract disorder with meconium & 0 & 6 & 6 & $39(35.75-44.5$ \\
\hline Others ${ }^{* 5}$ & 7 & 9 & 16 & $39.5(30-58.75)$ \\
\hline
\end{tabular}

${ }^{a} A P H$ antepartum hemorrhage, ${ }^{b} N R F H B P$ nonreassuring fetal heart beat pattern, ${ }^{c} C P D$ cephalopelvic disproportion, ${ }^{*} V B A C$ vaginal delivery after cesarean delivery,

${ }^{*}$ others (eclampsia, severe preeclampsia, repaired vesico-vaginal fistula at labor, obstructed labor, failed instrument)

\section{Pre-operative and operative related characteristics}

Among the study participants, 23(7.1\%) required stabilization before the operation, and 19 (5.8\%) were delayed in obtaining operation consent. Material needed for EmCS preparation was available at the labor and delivery ward for 286 (88\%) women and the operation Tables (OR table) were busy for nine $(2.8 \%)$ cases.

\section{Proportion of recommended decision to delivery interval}

The recommended decision to delivery interval was found to be $66(20.3 \%)$ with [95\% CI =15.9-24.7] of EmCS. The median (IQR) time of DDI was 40 (34-50) minutes. Emergency cesarean section was not performed in 44 (13.5\%) women until $1 \mathrm{~h}$ after the decision time (Fig. 1). The proportion of decision to delivery interval was almost similar in relation to the day of the decision for EmCS, with $20.8 \%$ on weekdays and $19 \%$ on weekends and public holidays.

\section{Factor associated with decision to delivery interval}

In the bivariable analysis, residence, referral from another institution, transfer time, the status of surgeons, type of anesthesia, operation time, and time of decision were statistically significant at $p$-value $<0.25$ level of significance. Residence, referred from other institutions, transfer time, the status of surgeons, type of anesthesia, and time of decision remained significant in the multivariable model. Women who were transferred to the operation theater before 15 min were 5.26 times more likely to have recommended DDI than women who were transferred after $15 \mathrm{~min}$ [AOR $=5.26,95 \% \mathrm{CI}=2.65-$ 10.46]. In addition, women whose EmCS was performed under general anesthesia were 4 times more likely to have recommended DDIs than women who were performed under regional anesthesia $[\mathrm{AOR}=4,95 \% \mathrm{CI}=$ 1.6-10]. The findings showed that EmCS performed in the daytime generally had a shorter DDI when compared with the nighttime $[\mathrm{AOR}=2.49,95 \% \mathrm{CI}=1.26-4.92]$ (Table 4).

\section{Discussion}

This study found that $20.3 \%$ of EmCS were performed within the recommended time interval of DDI. This is in

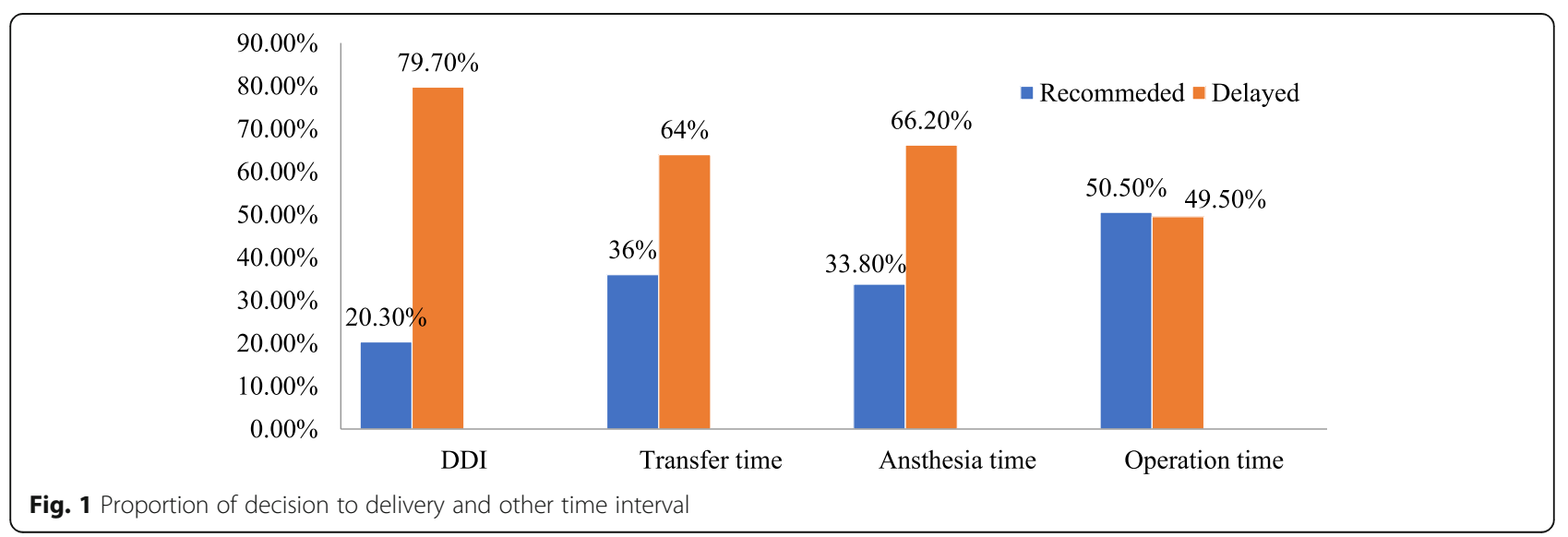


Table 4 Bivariate and multivariate analysis of factor affecting decision to delivery time interval $(n=325)$

\begin{tabular}{|c|c|c|c|c|}
\hline \multirow[t]{2}{*}{ Variables } & \multicolumn{2}{|c|}{ Decision to delivery Interval } & \multirow[t]{2}{*}{$\operatorname{COR}(95 \% \mathrm{Cl})$} & \multirow[t]{2}{*}{$\operatorname{AOR}(95 \% \mathrm{Cl})$} \\
\hline & $\leq 30 \min \mathrm{n}(\%)$ & $>30 \min n(\%)$ & & \\
\hline \multicolumn{5}{|l|}{ Residence } \\
\hline Urban & 54 & 174 & $2.19(1.1-4.33)$ & \\
\hline Rural & 12 & 85 & 1 & \\
\hline \multicolumn{5}{|l|}{ Referred } \\
\hline No & 27 & 68 & $1.94(1.1-3.41)$ & $2.50(1.26-5.0)^{*}$ \\
\hline Yes & 39 & 191 & 1 & \\
\hline \multicolumn{5}{|c|}{ Transfer Time } \\
\hline$\leq 15 \min$ & 48 & 69 & 7.34(3.99-13.48) & $5.26(2.65-10.46)^{* *}$ \\
\hline$>15 \min$ & 18 & 190 & 1 & \\
\hline \multicolumn{5}{|c|}{ Status of Surgeons } \\
\hline Senior & 43 & 88 & $5.86(2.7-12.68)$ & $2.95(1.3-6.7)^{*}$ \\
\hline Resident & 9 & 108 & 1 & \\
\hline IESO & 14 & 63 & $2.67(1.09-6.5)$ & $0.67(0.24-1.85)$ \\
\hline \multicolumn{5}{|c|}{ Anesthesia type } \\
\hline General & 14 & 24 & $2.63(1.28-5.44)$ & $4(1.6-10)^{*}$ \\
\hline Regional & 52 & 235 & 1 & \\
\hline \multicolumn{5}{|c|}{ Operation time } \\
\hline$\leq 5 \min$ & 38 & 126 & $1.43(1.2-2.5)$ & \\
\hline$>5 \min$ & 28 & 133 & 1 & \\
\hline \multicolumn{5}{|c|}{ Time of Decision } \\
\hline Day & 46 & 139 & $1.98(1.12-3.54)$ & $2.5(1.26-4.92)^{*}$ \\
\hline Night & 20 & 120 & 1 & \\
\hline
\end{tabular}

line with a study conducted in Gondar, Ethiopia, which was $19.3 \%$ [19]. This may be due to the similarity in the accessibility of logistics in hospitals and the practice and experience of professionals. This finding is less than that of studies conducted in Denmark and Oman with recommended DDIs of 87.5 and $60.8 \%$, respectively [7, 20]. The difference may be due to general infrastructure and economic differences in general from those countries. Specifically, in Denmark, a full-scale simulation and color-based multidisciplinary operative room team training was provided over the country to shorten the DDI. In Oman, programs were designed and implemented to shorten DDIs. On the other hand, this finding is greater than that of a study conducted in Nigeria, which was $0.9 \%$ of EmCS. This discrepancy may be due to a lack of funds for surgical materials and the absence of postservice billing in the study area of Nigeria, as patients' relatives usually pay surgical fees before the operation is performed. The findings of this research were also greater than those of studies conducted in Tanzania and Kenya, which were 12 and 3\%, respectively $[8,10]$. The difference may be that studies in both countries were conducted before the initiation of saving lives through the SaLTS) initiative in East Africa, which was started in late 2016.

In this study, women who were transferred to the operating room before $15 \mathrm{~min}$ showed a statistically significant association with recommended DDI than women who were transferred after $15 \mathrm{~min}$. This finding was consistent with study findings in India, Nigeria, Kenya, and Gondar, Ethiopia [9, 10, 19, 21, 22].

This study found that women whose EmCS was performed under general anesthesia were four times more likely to have recommended DDIs than women who were performed under regional anesthesia. The findings of this study were in line with those of studies conducted in Israel, Saudi Arabia, Indonesia, and Norway, which showed that general anesthesia shortened the DDI compared to regional anesthesia [17, 23-25]. The similarity may be a delay in regional anesthesia as a result of technical problems in inducing [9, 22, 24], and stabilization of clients before regional anesthesia is needed [18].

Emergency $\mathrm{C} / \mathrm{S}$ performed in the daytime generally had a shorter DDI when compared with the night time. This result was comparable to two consecutive studies 
conducted in Singapore $(p<0.05)[21,26]$. However; studies conducted in Norway, Thailand, and Uganda stated that EmCS performed during the daytime had prolonged DDI than those performed at night [23, 27, 28]. The increased number of staff during the daytime for emergency response than night and easy accessibility of logistics and laboratory even from private at day time in our study setting may explain the difference. In the study areas of Thailand and Uganda during daytime operation, the tables were occupied by elective surgery $[27,28]$.

Women whose EmCS was performed by seniors were two-point nine times more likely to have recommended DDIs than those made by residents. The same result was observed in Norway, with a mean duration difference of 6 min [23]. This could be because seniors were more experienced and had more exposure than residents. A Study in Singapore and Hong Kong showed no significant differences in DDI between senior surgeons and residents. The presence of regular daily drills for residents in both Singapore and Hong Kong study settings may explain this difference [21, 29].

Women who were directly admitted at these hospitals had two-point-five times more likely to have recommended DDI as compared to those who were admitted after referred from other institutions. As the investigators reviewed, no studies were conducted for comparison. The result may be explained referral cases may be more complicated and may need stabilization before the operation.

\section{Limitations of the study}

The study is prone to Hawthorne effects; the health care provider may know they are being observed in a research study their behavior may be influenced by what they assume to be the researcher's expectations, and observer bias may also affect our outcome of interest. This study does not address the short-and long-term effects of DDI on feto-maternal outcomes.

\section{Conclusion}

Decision-to-delivery interval within the recommended time is not achieved. Being a referral, time of day of EmCS, type of anesthesia, time taken for client preparation and transfer to the operation theater, and the status of surgeons are associated factors of DDI. Hence, to address institutional delays in EmCS, providers and facilities should be prepared in advance and ready for rapid emergency action.

\section{Abbreviations}

AOR: Adjusted odds ratio; Cl: Confidence interval; CS: Cesarean section; DDI: Decision to delivery interval; EmCS: Emergency cesarean section

\section{Supplementary Information}

The online version contains supplementary material available at https://doi. org/10.1186/s12884-021-03706-8.

\section{Additional file 1.}

\section{Acknowledgments}

The author's gratitude goes to Bahir Dar University, College of Medicine and Health Sciences, for giving us the opportunity to carry out this project. The authors would also like to extend their gratitude to data collectors, supervisors, study participants, and study facility staff for their honest and kind cooperation.

\section{Authors' contributions}

$\mathrm{TM}^{1}$ designed the study, performed the statistical analysis, and participated in the writing of the manuscript. $\mathrm{SK}^{2}, \mathrm{FA}^{2}, \mathrm{SAG}^{2}, \mathrm{BNG}^{3}$ and $\mathrm{ASE}^{3}$ reviewed the manuscript for intellectual content and provided technical guidance in the statistical analysis. All authors read and approved the final manuscript.

Funding

No funding.

\section{Availability of data and materials}

The datasets analyzed during the current study are available from the corresponding author upon reasonable request.

\section{Declarations}

Ethics approval and consent to participants

Ethical approval was obtained from the ethical review committee of the College of Medicine and Health Sciences, Bahir Dar University. Written informed consent was obtained from participant before the interviews.

\section{Consent for publication}

Not applicable.

\section{Competing interests}

The authors declare that they have no competing interests.

\section{Author details}

${ }^{1}$ Department of Midwifery, College of Health Science, Debre Berhan University, Debre Berhan, Ethiopia. ${ }^{2}$ School of Health Sciences, College of medicine and health science, Bahir Dar University, Bahir Dar, Ethiopia.

${ }^{3}$ Department of Nursing, College of Health Science, Debre Berhan University, Debre Berhan, Ethiopia.

Received: 8 October 2020 Accepted: 10 March 2021

Published online: 20 March 2021

References

1. Soltanifar S, Russell R. The National Institute for health and clinical excellence (NICE) guidelines for caesarean section, 2011 update: implications for the anaesthetist. Int J Obstet Anesth. 2012;21(3):264-72. https://doi.org/10.1016/j.ijoa.2012.03.004.

2. Gholitabar M, Ullman R, James D, Griffiths M. Caesarean section: summary of updated NICE guidance. BMJ. 2011;343(nov23 1):d7108. https://doi.org/1 $0.1136 /$ bmj.d7108

3. Cunningham FG, Leveno KJ, Bloom SL, Spong CY, Dashe JS, Hoffman BL, Casey BM, Sheffield JS. Williams obstetrics 24 edition. 24th ed. New York: McGraw-Hill Education eBooks New York; 2014.

4. Obstetricians ACo, Safety GCoP. Improvement Q: ACOG Committee Opinion No. 487: preparing for clinical emergencies in obstetrics and gynecology. Obstet Gynecol. 2011;117(4):1032-4. https://doi.org/10.1097/AOG.0b013e31 821922eb.

5. Organization $\mathrm{WH}$. WHO recommendations non-clinical interventions to reduce unnecessary caesarean sections: World Health Organization; 2018.

6. Health FMo. Management protocol on selected obstetrics topics: Federal Democratic Republic of Ethiopia; 2010.

7. Tashfeen K, Patel M, Hamdi IM, Al-Busaidi IH, Al-Yarubi MN. Decision-todelivery time intervals in emergency caesarean section cases: repeated 
cross-sectional study from Oman. Sultan Qaboos Univ Med J. 2017;17(1): e38-42. https://doi.org/10.18295/squmj.2016.17.01.008.

8. Hirani BA, Mchome BL, Mazuguni NS, Mahande MJ. The decision delivery interval in emergency caesarean section and its associated maternal and fetal outcomes at a referral hospital in northern Tanzania: a cross-sectional study. BMC Pregnancy Childbirth. 2017;17(1):411. https://doi.org/10.1186/s12 884-017-1608-x.

9. Radhakrishnan G, Yadav G, Vaid NB, Ali H. Factors affecting "decision to delivery interval" in emergency caesarean sections in a tertiary care hospital: a cross sectional observational study. Int J Reprod Contracept Obstet Gynecol. 2013;2(4):651-6. https://doi.org/10.5455/2320-1770.ijrcog20131231.

10. Kamotho D, Pertet A, Ogwayo I. Decision to incision interval for emergency caesarean section and postoperative outcomes in a resource limited rural Kenyan public hospital. Int J Reprod Contraception Obstetrics Gynecology. 2018;7(7):2573. https://doi.org/10.18203/2320-1770.ijrcog20182863.

11. Owonikoko K, Olabinjo A, Bello-Ajao H, Adeniran M, Ajibola T. Determinants of Decision to Delivery Interval (DDI) in Emergency Caesarean Sections in Ladoke Akintola University of Technology Teaching Hospital Ogbomoso, Nigeria. Clin Mother Child Health. 15:294. https://doi.org/10.4172/20907214.1000294 Page 2 of 5 Clinics Mother Child Health, an open access journal ISSN: 2090-7214 Volume 15 Issue 2• 1000294. surgeries was 2018: 152.152-169.155

12. Ayano B, Guto A: Indications and outcomes of emergency caesarean section at St Paul's HospitalMedical college, Addis Ababa, Ethiopia 2017 (afoul month retrospective cohort study). investigation in gynecology research and women health 2018.

13. Abebe FE, Gebeyehu AW, Kidane AN, Eyassu GA. Factors leading to cesarean section delivery at Felegehiwot referral hospital, Northwest Ethiopia: a retrospective record review. Reprod Health. 2015;13(1):6. https:// doi.org/10.1186/s12978-015-0114-8.

14. Fesseha N, Getachew A, Hiluf M, Gebrehiwot Y, Bailey P. A national review of cesarean delivery in Ethiopia. Int J Gynecol Obstet. 2011;115(1):106-11. https://doi.org/10.1016/j.jigo.2011.07.011.

15. Heller G, Bauer E, Schill S, Thomas T, Louwen F, Wolff F, Misselwitz B, Schmidt S, Veit C. Decision-to-delivery time and perinatal complications in emergency cesarean section. Dtsch Arztebl Int. 2017;114(35-36):589-96. https://doi.org/10.3238/arztebl.2017.0589.

16. Hughes NJ, Namagembe I, Nakimuli A, Sekikubo M, Moffett A, Patient CJ, Aiken CE. Decision-to-delivery interval of emergency cesarean section in Uganda: a retrospective cohort study. BMC Pregnancy Childbirth. 2020;20:1-10.

17. Guntur N. The recommended time interval of decision to incision in caesarean section is not achieved in daily practice. Indonesian J Obstet Gynecol. 2013.

18. Mishra N, Gupta R, Singh N. Decision delivery interval in emergency and urgent caesarean sections: need to reconsider the recommendations? J Obstet Gynecol India. 2018;68(1):20-6. https://doi. org/10.1007/s13224-017-0991-6.

19. Temesgen MM, Gebregzi AH, Kasahun HG, Ahmed SA, Woldegerima YB. Evaluation of decision to delivery time interval and its effect on fetomaternal outcomes and associated factors in category-1 emergency caesarean section deliveries: prospective cohort study. BMC Pregnancy Childbirth. 2020;20(1):164. https://doi.org/10.1186/s12884-020-2828-z.

20. Fuhrmann L, Pedersen T, Atke A, Møller A, Østergaard D. Multidisciplinary team training reduces the decision-to-delivery interval for emergency caesarean section. Acta Anaesthesiol Scand. 2015;59(10):1287-95. https://doi. org/10.1111/aas.12572.

21. Wong TCT, Lau CQH, Tan EL, Kanagalingam D. Decision-to-delivery intervals and total duration of surgery for caesarean sections in a tertiary general hospital. Singap Med J. 2017;58(6):332-7. https://doi. org/10.11622/smedj.2016098.

22. Bello FA, Tsele TA, Oluwasola TO. Decision-to-delivery intervals and perinatal outcomes following emergency cesarean delivery in a Nigerian tertiary hospital. Int J Gynecol Obstet. 2015;130(3):279-83. https://doi.org/10.1016/j. ijgo.2015.03.036

23. Kolås T, Hofoss D, Øian P. Predictions for the decision-to-delivery interval for emergency cesarean sections in Norway. Acta Obstet Gynecol Scand. 2006; 85(5):561-6. https://doi.org/10.1080/00016340600589487.

24. Weiner E, Bar J, Fainstein N, Ben-Haroush A, Sadan O, Golan A, Kovo M. The effect of a program to shorten the decision-to-delivery interval for emergent cesarean section on maternal and neonatal outcome. Am J Obstet Gynecol. 2014;210(3):224. e221-6.
25. Sait KH. The decision to delivery interval in emergency and non-urgent caesarean sections at king Abdulaziz University hospital. J King Abdulaziz Univ. 2011;98(282):1-16.

26. Dunn CN, Zhang Q, Sia JT, Assam PN, Tagore S, Sng BL. Evaluation of timings and outcomes in category-one caesarean sections: a retrospective cohort study. Indian J Anaesthes. 2016;60(8):546-51. https://doi.org/10.4103/ 0019-5049.187782.

27. Nakintu E, Murokora D. Emergency caesarean sections: decision to delivery interval and obstetric outcomes in Nsambya hospital, Uganda-A Cross Sectional Study. J Gynecol. 2016;1(4):122.

28. Khemworapong K, Sompagdee N, Boriboonhirunsarn D. Decision-todelivery interval in emergency cesarean delivery in tertiary care hospital in Thailand. Obstet Gynecol Sci. 2018;61(1):48-55. https://doi.org/10.54 68/ogs.2018.61.1.48.

29. S-L MAK, FHKCOG FO. Maternal and fetal outcomes in extremely urgent caesarean delivery in relation to the decision-to-delivery interval. J Gynaecol Obstet Midwifery. 2015;15(1):16-22.

\section{Publisher's Note}

Springer Nature remains neutral with regard to jurisdictional claims in published maps and institutional affiliations.

\section{Ready to submit your research? Choose BMC and benefit from:}

- fast, convenient online submission

- thorough peer review by experienced researchers in your field

- rapid publication on acceptance

- support for research data, including large and complex data types

- gold Open Access which fosters wider collaboration and increased citations

- maximum visibility for your research: over $100 \mathrm{M}$ website views per year

At BMC, research is always in progress.

Learn more biomedcentral.com/submissions 